\title{
Cervical Fracture During COVID-19 Pandemic Era: A Case Series
}

\author{
Pamudji Utomo (iD \\ R Andhi Prijosedjati' \\ Ricat Hinaywan Malik (D) ${ }^{2}$ \\ 'Department of Orthopedics \& \\ Traumatology, Prof. Dr. R. Soeharso \\ Orthopedic Hospital/Faculty of Medicine, \\ Universitas Sebelas Maret, Surakarta, \\ Indonesia; ${ }^{2}$ Orthopedics \& Traumatology, \\ Faculty of Medicine, Universitas Sebelas \\ Maret, Surakarta, Indonesia
}

\begin{abstract}
Background: Cervical fractures are potentially serious and can have fatal consequences if not treated properly. Correct diagnosis and classification of injury is the first step in determining the most appropriate treatment. Cervical fractures will have an impact on the patient's work, and COVID-19 is a challenge in the hospital to treat a cervical fracture. This study aims to discuss the case of patients with cervical fractures that have undergone surgical treatment in the COVID-19 pandemic.

Case Presentation: Two cases of emergency patients with cervical injury treated at the hospital in the acute setting of the COVID-19 pandemic. All these patients experienced delayed timing to arrive in the emergency department of Prof. Dr. R. Soeharso Orthopedic Hospital. Neurological outcome was assessed before being discharged after surgery and a 3-month follow-up post-surgery.

Results: Laminectomy and posterior stabilization and fusion (PSF) were performed immediately after diagnosis was established in both patients. Physical rehabilitation was performed. In a 3-month follow-up, both patients' neurological functions improved.

Conclusion: Clinical outcomes of cervical injury patients can be affected by some factors, for example, timing to diagnosis, timing to traction application, timing to surgery, and timing to rehabilitation. Depending on the institution, weekend days can also affect the delay of the COVID-19 PCR swab. MRI schedule and patient optimal condition can also affect the timing to surgery. The immediate diagnosis and prompt treatment are needed to make a better outcome, especially better neurological status.
\end{abstract}

Keywords: cervical fracture, COVID-19, diagnosis, treatment, outcome

\section{Introduction}

Accidents are the 4th cause of death after heart disease, cancer, and stroke. There are 50 deaths due to accidents per 100,000 population each year; $3 \%$ of these deaths are due to direct spinal cord trauma and $2 \%$ due to multiple traumas. ${ }^{1}$ There is a bimodal age distribution among patients with spinal cord injuries: the first peak occurs between 15 and 24 years, and the second in patients over 55 years. ${ }^{2,3}$

Spinal injury with or without neurologic deficits should always be considered in patients with multiple traumas. Approximately $5 \%$ of patients with head injuries also have spinal injuries while $25 \%$ of patients with spinal injuries have at least a minor head injury. Approximately $55 \%$ of spinal injuries occur in the cervical region, $15 \%$ in the thoracic region, $15 \%$ in the thoracolumbar joint region, and $15 \%$ in the lumbosacral region. Approximately $10 \%$ of patients with cervical spine traumas have an unrelated second vertebral column fracture. The location of the fracture or the cervical fracture-dislocation was mostly at $\mathrm{C} 2$ followed by $\mathrm{C} 5$ and
Correspondence: Pamudji Utomo Department of Orthopedics and Traumatology, Faculty of Medicine, Universitas Sebelas Maret, JI. Ir. Sutami

36A, Surakarta, Indonesia

Tel +62 271 644178

Email pamudji_utomo@staff.uns.ac.id 
C6, especially at the age of 3 decades. ${ }^{1}$ Cervical injury can be defined as persistent impairments caused by dysfunction of the somatosensory system of the cervical spine. ${ }^{4}$ In the subaxial region, approximately $40 \%$ of all injuries are localized to $\mathrm{C} 6$ or $\mathrm{C} 7$. This area is also commonly involved in extension-type injuries. ${ }^{5,6}$

Spinal injuries occur due to vertebral fractures and mostly involve the cervical and lumbar. Injuries occur because of hyperflexion, hyperextension, compression, or rotation of the spine. Secondary disorders can be caused by hypoxemia and ischemia. Ischemia is caused by hypotension, edema, or compression. Damage to the spinal is permanent because there is no regeneration of the nerve tissue. ${ }^{7}$

Acute mortality after cervical spine trauma can vary. In the United States, one study found the overall rate to be around $2.5 \%$ and more than $10 \%$ of those involved the spinal cord. ${ }^{8}$ In Norway, from 2009 to 2012, the 1st- and 3rd-month mortality rates were higher, $4 \%$ and $6 \%$, respectively. Some have identified cervical fracture as a key event in the elderly, like hip fracture, in terms of its effect on morbidity and mortality. ${ }^{5,9,10}$

Cervical fractures are potentially serious and can have fatal consequences if not treated properly. Correct diagnosis and classification of injury is the first step in determining the most appropriate treatment, which can be surgical or conservative. ${ }^{5,9,10}$

On March 11, 2020, the World Health Organization (WHO) declared the COVID-19 pandemic. Low- and middle-income countries with less developed health systems are likely to face more significant challenges and remain vulnerable in controlling COVID-19 compared to the high-income countries. ${ }^{11}$ Cervical fractures will have an impact on the patient's work, and COVID-19 is a challenge for the hospital to treat a cervical fracture.

This case series aims to discuss the case of patients with cervical fractures that have undergone surgical treatment in the COVID-19 pandemic.

\section{Case Presentation}

The patient was searched from March 2020February 2021 during the COVID-19 pandemic. There were 12 patients with cervical injuries that performed surgery in Prof. Dr. Soeharso Orthopedic Hospital, but only 2 patients were still alive and could be contacted. This study has obtained ethical clearance approval from the hospital ethical team. Written informed consent for publication of their details was obtained from the family.

\section{Case I}

A man, 55 years old, came to the emergency department with a chief complaint of weakness in his four extremities. Two days before admission, he fell from a tree about 6 meters in height, where his back hit the branch of the tree. After the accident, the patient had a complaint of back pain and weakness of his four extremities. He was brought to the local surgery hospital and advised to perform an MRI of the cervical region in the hospital which has MRI. After performing MRI, the patient was advised to go to Prof. Dr. Soeharso Orthopedic Hospital.

From the primary survey, ABCDE was clear. Vital signs of the patient included BP 126/65 mmHg, HR 73x/ $\mathrm{m}, \mathrm{RR} 18 \mathrm{x} / \mathrm{m}$ thoracoabdominal pattern, and temperature at $36.6^{\circ} \mathrm{C}$. In the spine region, the skin was intact with a swelling and kyphotic deformity. Tenderness was found in the midline of the lower cervical region with a step-off and neurological deficit. ROM of the spine was not performed. From the neurological examination, the upper motoric scale was 2 both right and left; the lower motoric scale was 4 both right and left. The patient had hypoesthesia below the level of $\mathrm{C} 4$ dermatome. There was a normal physiological reflex and no pathological reflex. Bulbocavernosus reflex and sacral sparing were positive.

The radiological examination in Figure 1 does not show a fracture or dislocation in the AP and lateral view of cervical X-ray while the lateral view only shows the C6 vertebra clearly.

Figure 2 shows a fracture but does not show dislocation between $\mathrm{C} 7$ and $\mathrm{T} 1$ vertebra. There is also a mild compression in the spinal cord at the levels of C4-C6. Therefore, the initial assessments in the emergency department were:

1. Spinal Cord Injury Incomplete Type in C4 Vertebra, Central Cord Syndrome, AIS C.

2. Bilateral Facet Joint Dislocation of C7-T1 Vertebra, Allen Ferguson Flexion-Distraction Type Stage III, AIS C.

On day 3, the patient performed skull traction (GWT). Figure 3 does not show a dislocation between $\mathrm{C} 7$ and $\mathrm{T} 1$ vertebra. However, this picture could show $\mathrm{C} 7$ more clearly after the GWT application. The initial weight of $5 \mathrm{~kg}$ was applied and then increased to $7.5 \mathrm{~kg}$. The patient felt pain and discomfort, so the weight was maintained at $7.5 \mathrm{~kg}$ until the surgery was performed. 


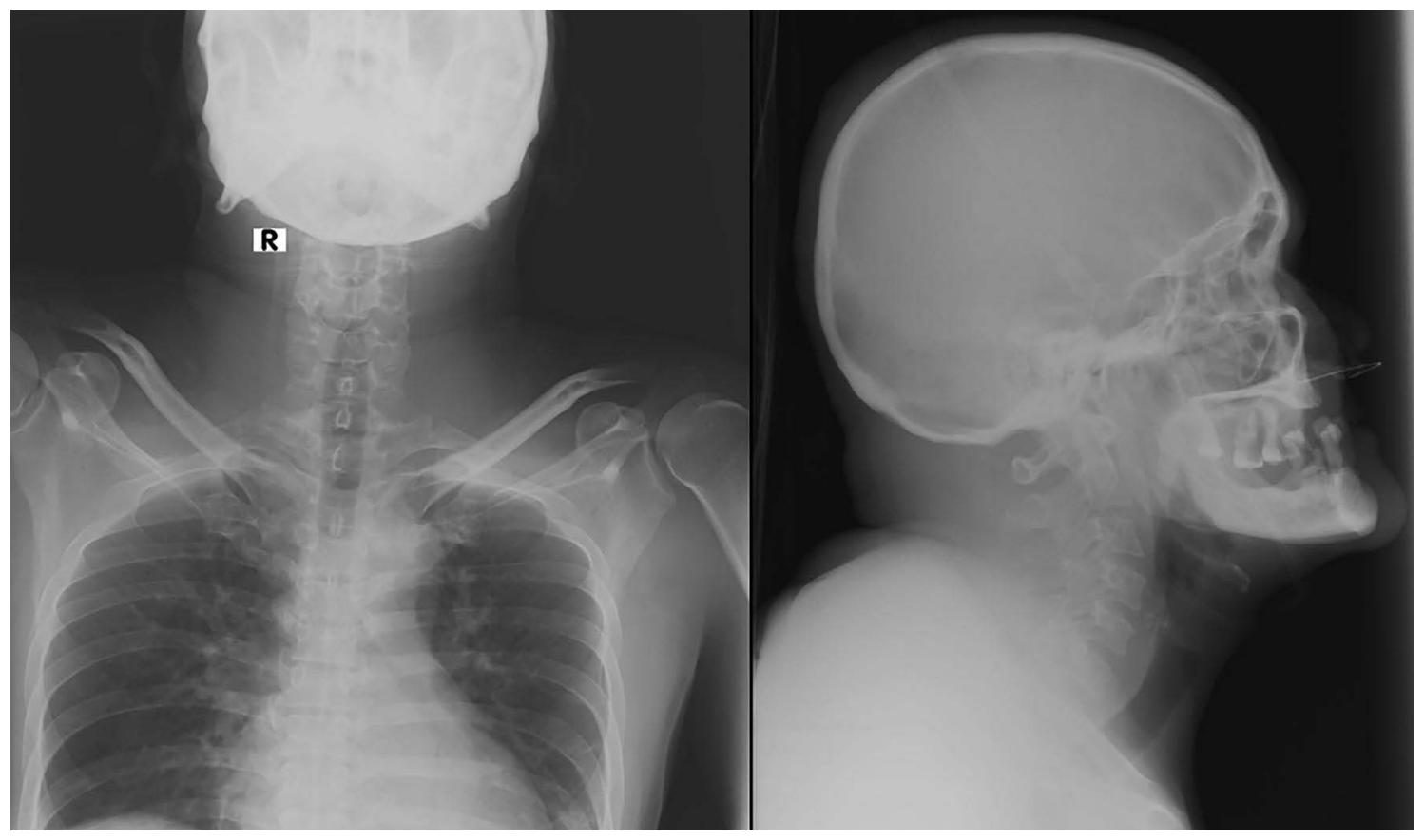

Figure I X-ray of cervical AP/lateral view in day-I of hospital admission from Case I.

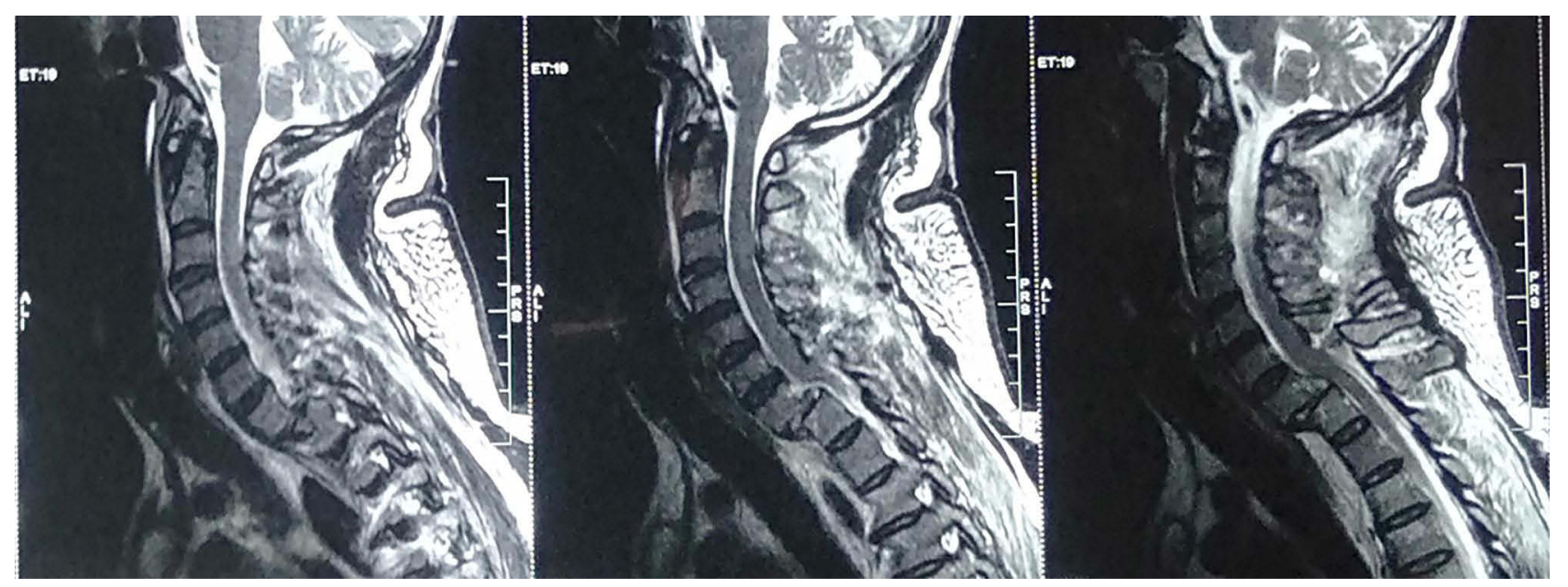

Figure 2 MRI of cervical in day-I of hospital admission from previous hospital.

Six days after admission, when the patient's condition was optimal, he underwent Decompression Laminectomy C7-T1 and PSF C5-T3 vertebra. The post-operative diagnosis was Fracture Dislocation C7-T1 Post Laminectomy + PSF C5-T3. Post-operative X-ray is shown in Figure 4.

After surgery, the patient was admitted to ICU for one day. His condition was always stable, so he was moved to the ward on the second-day post-surgery. He was treated with antibiotics, analgetic, calcium, and neuroprotector. There was no problem with his respiration and metabolism.
Physical \& rehabilitation medicine also plays an important role. Before surgery, the patient performed general exercise, bed exercise, dan breathing exercise. After surgery, there were some exercises on the different days:

Day 1-2: General exercise, upper and lower extremity exercise, breathing exercise, positioning, sit down mobilization on the bed.

Day 3: General exercise, upper and lower extremity exercise, breathing exercise, sit down mobilization.

Day 4: General exercise, upper and lower extremity exercise, core exercise, breathing exercise, transfer to 


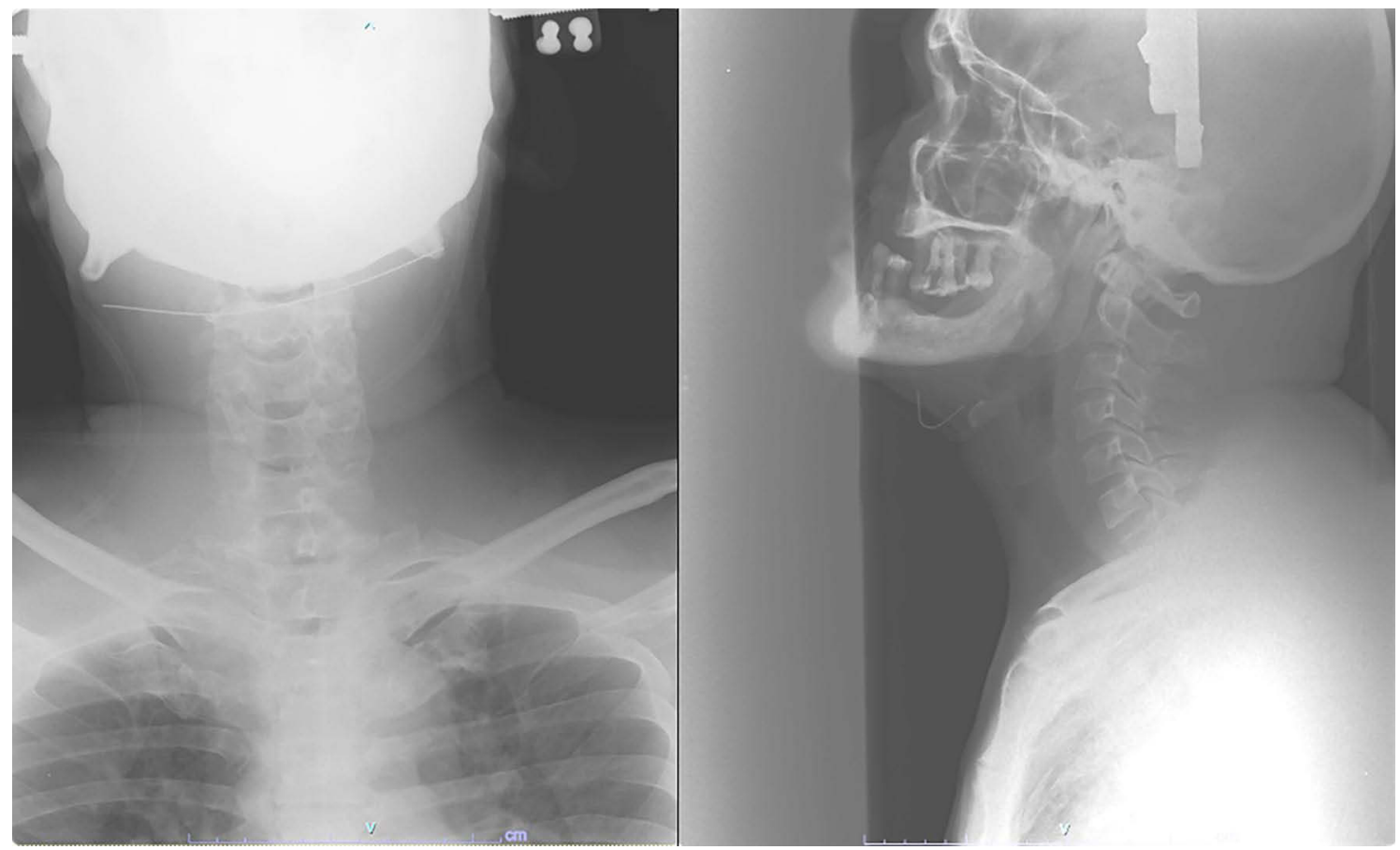

Figure 3 X-ray of cervical AP/lateral view after GWT application in day-3.

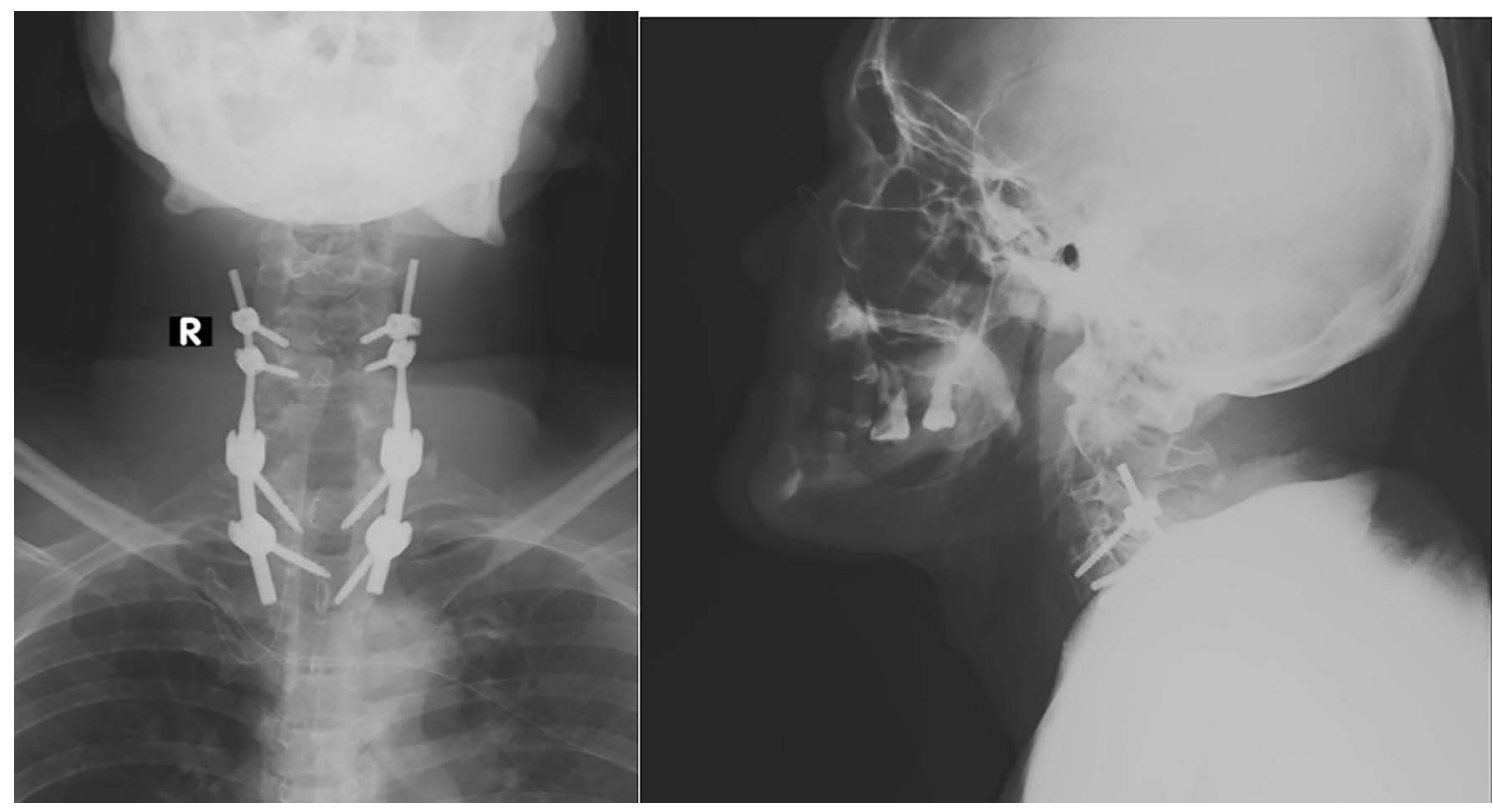

Figure $4 \mathrm{X}$-ray of cervical AP/lateral view post-operative from Case I.

a wheelchair. Additional occupation therapy included activity training and functional activity daily living.

Day 5: Collar neck and discharged.

In the COVID-19 pandemic, all patients who underwent surgery must have PCR swab examination with a negative result. This patient has performed a PCR swab for COVID-19 on day 2 (Feb 10) with a negative result and performed surgery on day 6 (Feb 15). He was hospitalized for 11 days (Feb 9-20). His neurological status after surgery compared with before surgery was improved.

\section{Case II}

A man, 37 years old, came to the emergency department with a chief complaint of weakness in his four extremities. 
Four days before admission, he fell from a roof about 4 meters in height with a supine position when hitting the floor. After the accident, he had a complaint of back pain and weakness of his four extremities. He was brought to Prof. Dr. Soeharso Orthopedic Hospital.

From the primary survey, his airway was clear. There were problems in breathing with an abdominal pattern of respiration and $\mathrm{SpO} 290 \%$ using NRM 10 Lpm of oxygen. There were problems in circulation with hypotension (BP 90/ $60 \mathrm{mmHg}$ ) and bradycardia (HR $58 \mathrm{x} / \mathrm{m}$ ). Other vital signs of the patient were $\mathrm{RR} 20 \mathrm{x} / \mathrm{m}$ and temperature at $36.9^{\circ} \mathrm{C}$. In the spine region, the skin was intact with a swelling and kyphotic deformity. Tenderness was found in the midline of the lower cervical region with a step-off and neurological deficit. ROM of the spine was not performed. From the neurological examination, the upper motoric scale from C5678T1 was 44422 both right and left, and the lower motoric scale from L2345S1 was 0 (zero). The patient had hypoesthesia below the level of C5 dermatome and anesthesia below C6 dermatome. There was a decrease in physiological reflex, and no pathological reflex was found. Bulbocavernosus reflex was positive whole sacral sparing and clonus was negative.

The radiological examination in Figure 5 does not show a fracture or dislocation in the AP and lateral view of cervical X-ray while the lateral view only shows half of the $\mathrm{C} 7$ vertebra clearly.

Therefore, the initial assessment in the emergency department included Spinal Cord Injury Incomplete Type in C5 Vertebra, Anterior Cord Syndrome, AIS A.
On day 5, the patient performed Cervical MRI. From Figure 6, there was only a fracture of the spinous process, and we can see dislocation between $\mathrm{C} 7$ and $\mathrm{T} 1$ vertebra. We can see also a mild compression in the spinal cord at the level of C5-C6. Thus, the assessments were:

1. Spinal Cord Injury Incomplete Type in C5 Vertebra, Anterior Cord Syndrome, AIS A.

2. Bilateral Facet Joint Dislocation of C7-T1 Vertebra, Allen Ferguson Flexion-Distraction Type Stage III, AIS A.

On day 7, the patient performed GWT. Figure 7 does not indicate a dislocation between $\mathrm{C} 7$ and $\mathrm{T} 1$ vertebra. It is like Figure 1 which shows only half of C7. The load weight was improved to $12.5 \mathrm{~kg}$. The patient felt pain and discomfort if the load weight was improved. The weight was maintained until the surgery was performed.

Eight days after admission, after the patient's condition was optimal, he underwent Decompression Laminectomy C7 and PSF C5-T2 vertebra. The post-operative diagnosis became Fracture Dislocation C7-T1 Post Laminectomy + PSF C5-T2. Post-operative X-ray is shown in Figure 8.

After surgery, the patient was admitted to ICU for one day. There was a problem with his respiration, so the patient used a ventilator in ICU for 1 day. There was a metabolic problem in which the bleeding during surgery was $1700 \mathrm{cc}$. Additional 2 PRC and vasoconstrictors from the anesthesia were admitted. When his condition was improved and stable, the patient was moved to the ward

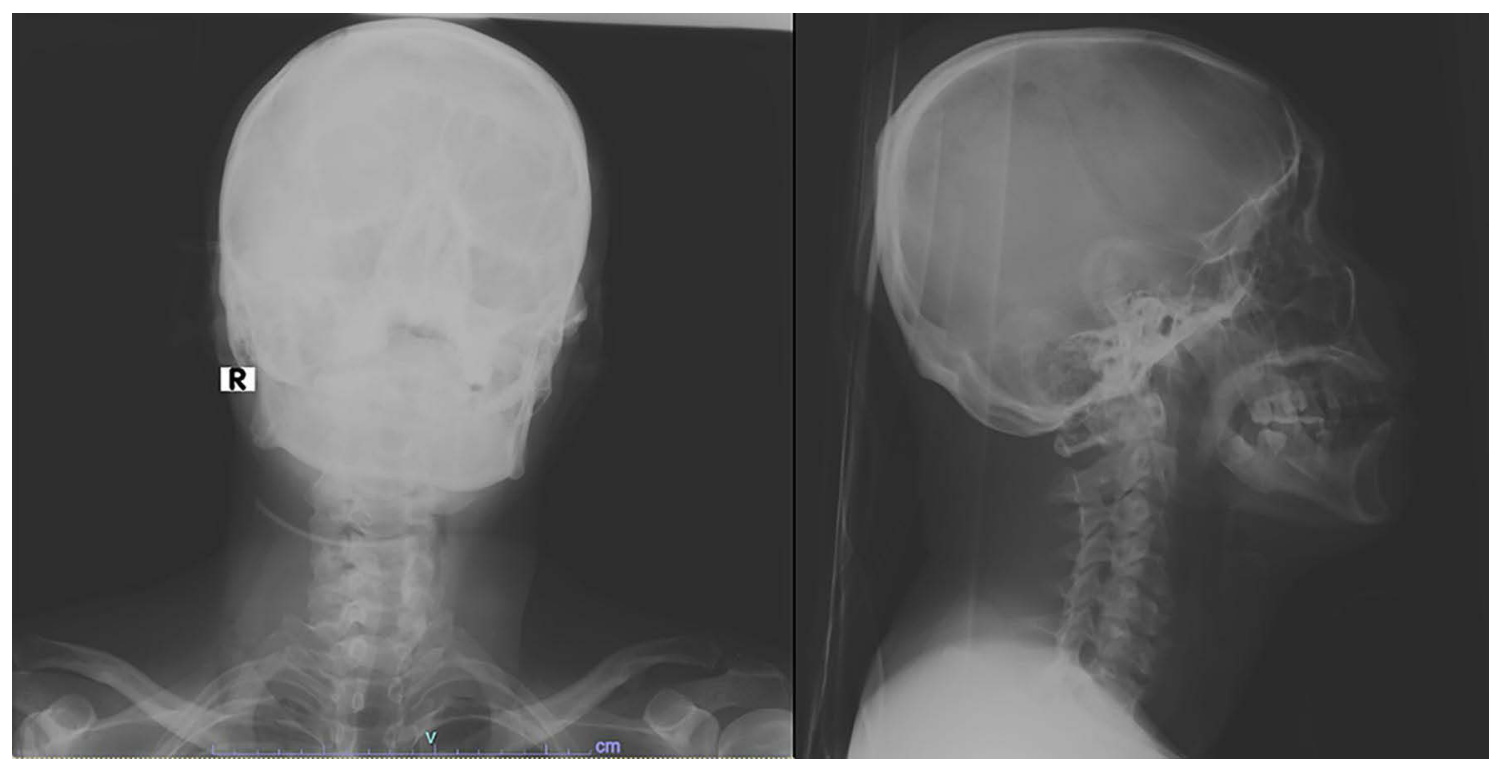

Figure 5 X-ray of cervical AP/lateral view in day-I of hospital admission from Case II. 


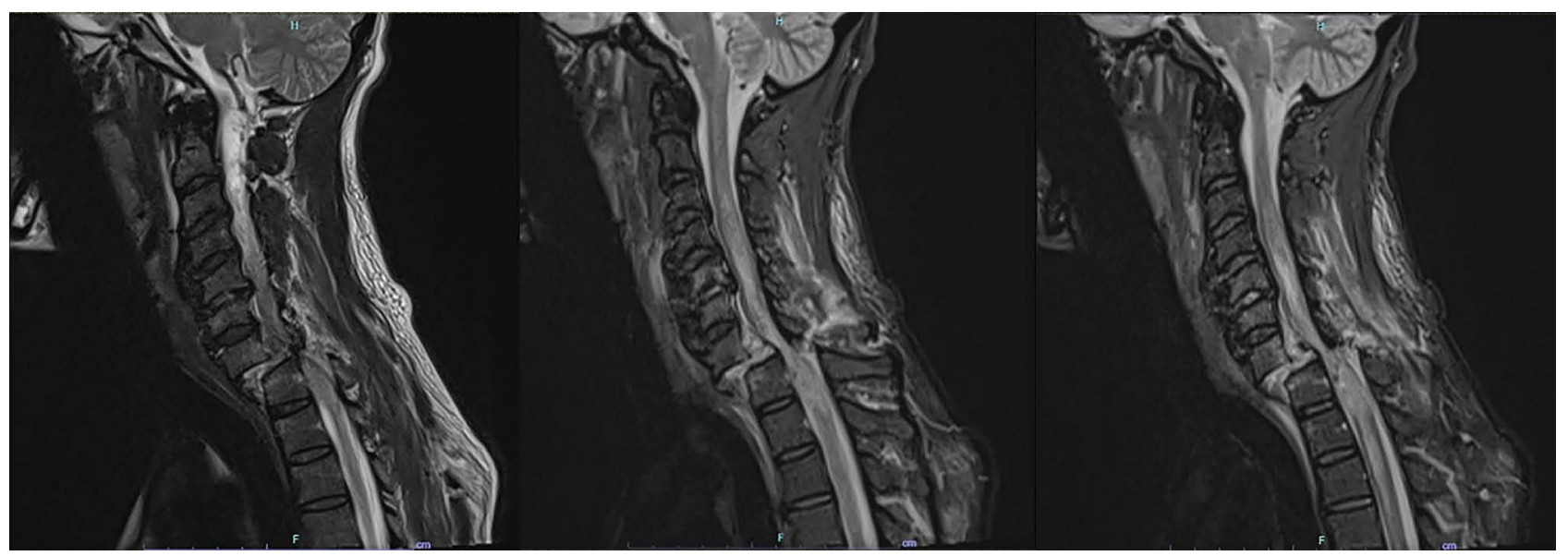

Figure $6 \mathrm{MRI}$ of cervical in day 5 after hospital admission.

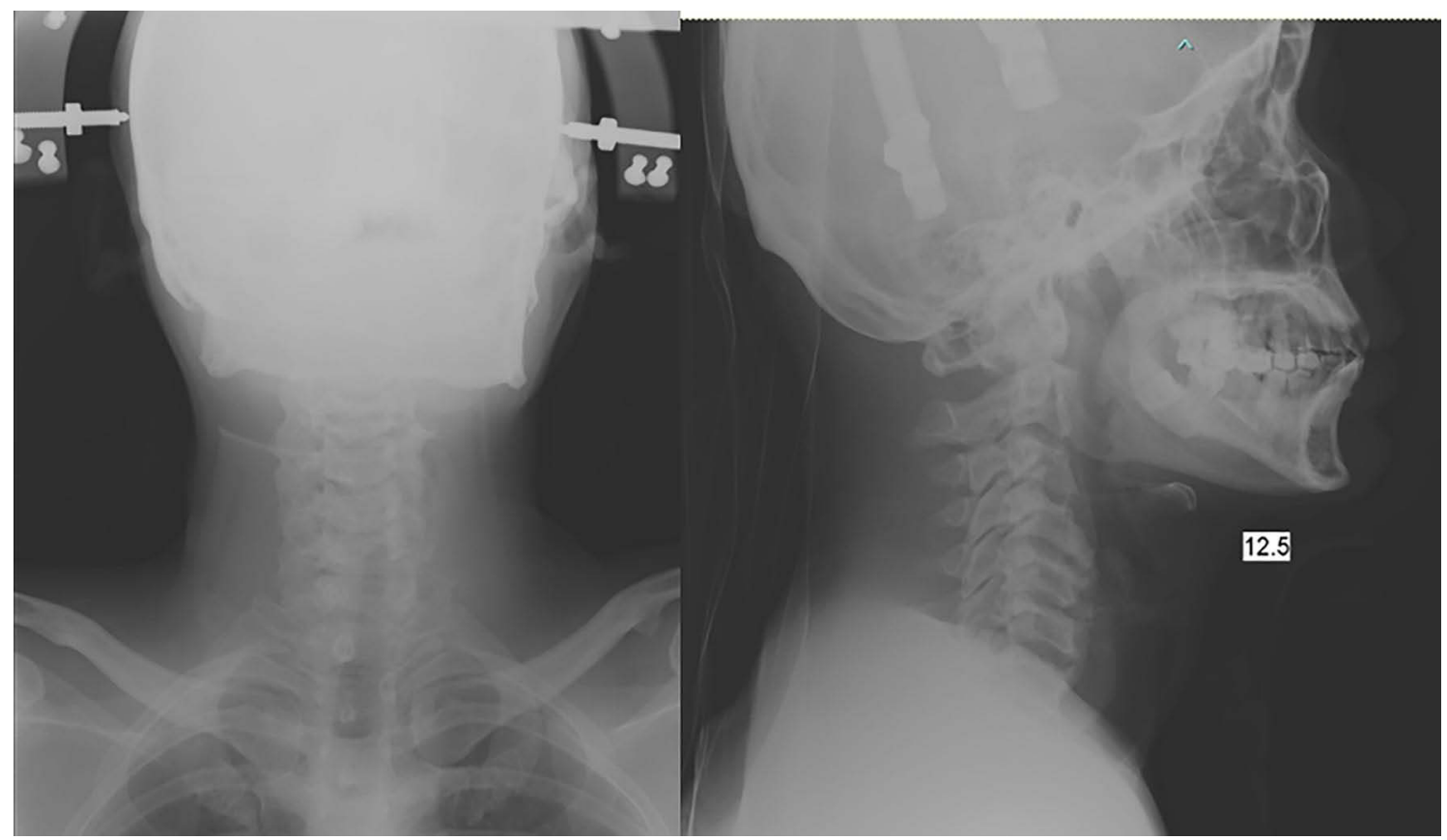

Figure 7 X-ray of cervical AP/lateral view after GWT application in day-7 of hospital admission.

on the second day post-surgery. He was treated with antibiotics, analgetic, calcium, and neuroprotector.

Physical \& rehabilitation medicine also plays an important role. Before surgery, on the first day, the patient performed general exercise, passive ROM exercise, breathing exercise, and positioning. On the second day to surgery, general exercise, bed exercise, physical exercise, and passive ROM exercise were performed. After surgery, there were some exercises on the different days:

Day 1-3: General exercise, bed exercise, breathing exercise, passive ROM exercise.
Day 4: General exercise, upper and lower extremity exercise, ROM exercise, breathing exercise, positioning.

Day 5-6: General exercise, upper and lower extremity exercise, active and passive ROM exercise, breathing exercise, sit down exercise, move to a wheelchair.

In the COVID-19 pandemic, all patients who underwent surgery must have PCR swab examination with a negative result. This patient has performed a PCR swab for COVID-19 on day 2 (Feb 5) with a negative result and performed surgery on day 8 (Feb 11). The patient was hospitalized for 14 days (Feb 4-17). The neurological 


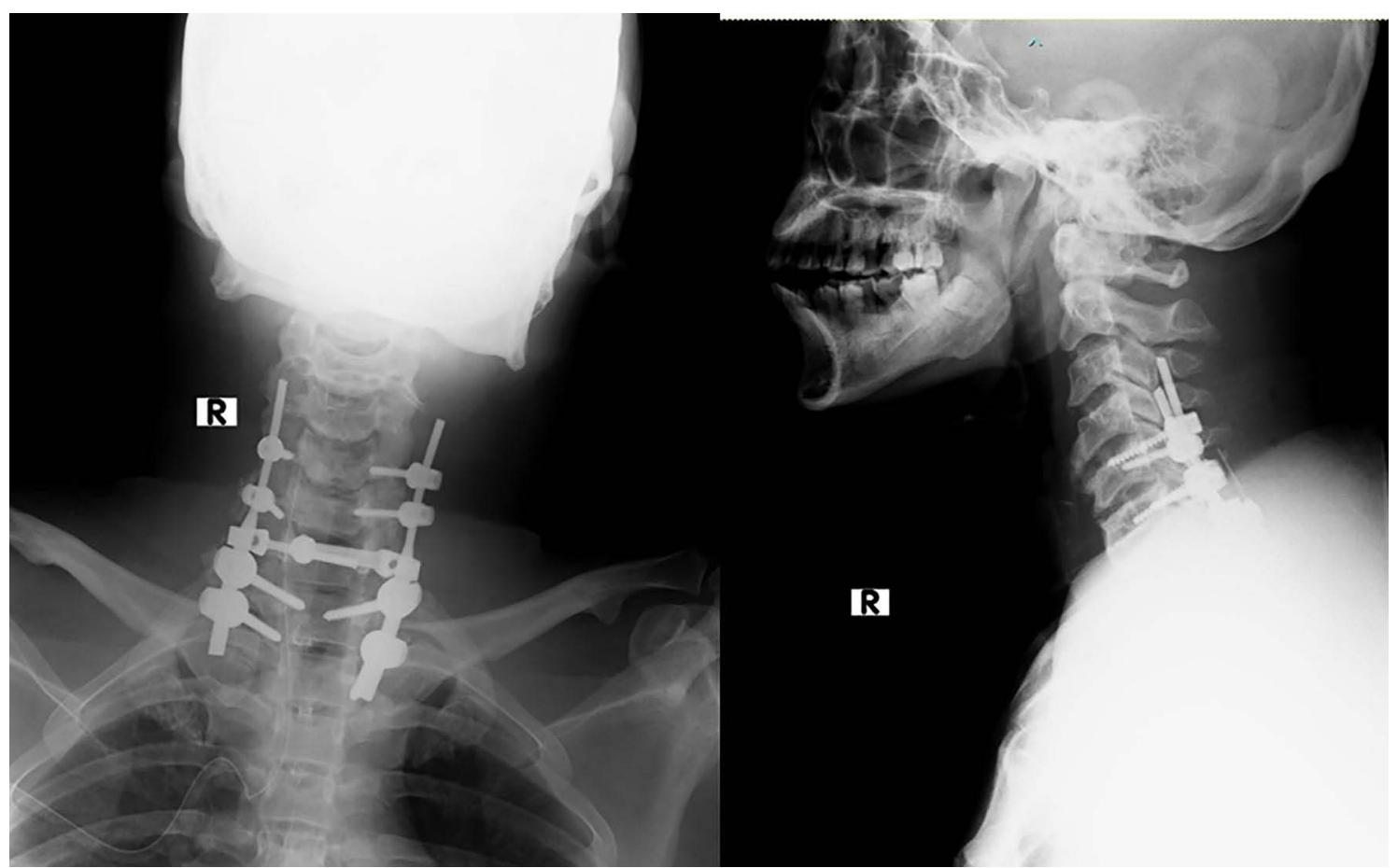

Figure 8 X-ray of cervical AP/lateral view post-operative from Case II.

status after surgery compared with before surgery was improved.

\section{Discussion}

During hospitalization after surgery, CASE I and CASE II have improved clinical outcomes in neurological status compared to pre-surgery. CASE I obtained MRI faster than CASE II, so CASE I got an earlier diagnosis than CASE II. The initial GWT application is earlier in CASE I than CASE II, day 3 vs day 7 of hospitalization, respectively. The timing of surgery in CASE I is earlier than in CASE II, day 6 vs day 8 of hospitalization, respectively.

Both patients in this article are classified as dislocation fracture with spinal cord injuries, with the treatment of surgery more than 3 days after the injury (CASE I vs CASE II, 8 days vs 12 days after injury, respectively). This delayed surgery will affect the clinical outcomes. Supported by Liu et al, they retrospectively analyzed the clinical outcomes of patients who underwent decompression within and after 72 hours. The study found that the rate of neurological function deterioration in the early decompression group was significantly higher than that of the late decompression group. ${ }^{12} \mathrm{Du}$ et al explore the optimal surgical decompression timing for different types of traumatic cervical spinal cord injury (CSCI) according to AO-Spine subaxial cervical spine injury classification.
Type A and F1-3 fractures are not required to undergo aggressive early decompression. Type $\mathrm{B}$ and $\mathrm{C} / \mathrm{F} 4$ fractures should receive early surgical treatment for better clinical outcomes. ${ }^{13}$

Both patients in this article underwent GWT application after MRI because plain X-ray does not clearly show a cervical dislocation. This delayed GWT will affect the clinical outcomes too. Wang et al wrote the timing of spinal column reduction remains controversial (early reduction may provide an improved chance of neurological recovery while the time to reduction is not a significant predictor of neurological recovery). Additionally, the ease and speed of obtaining an MRI evaluation vary between institutions; thus, individual assessment is needed to determine the appropriateness of pre-reduction MRI for patients with dislocated facets. For patients who are unable to fully cooperate with a neurological examination during attempted reduction of facets with spine traction, MRI is essential. For cooperative patients with facet dislocation without neurological deficit, prereduction MRI may be considered, given that emergent reduction is not necessary. For patients who have a neurological deficit, reduction with traction before MRI may be appropriate as the delay in a reduction associated with obtaining a prereduction MRI could be detrimental to the neurological status of the patient. ${ }^{14}$ 
When the author wrote this article (3-month follow-up post-surgery in CASE I \& II), the condition of CASE I was improved. From the motoric examination, the upper motoric scale was 3 both right and left, and the lower motoric scale was 4 both right and left. He could do mobilization with a wheelchair. On the other side, the condition of CASE II was minimally improved. From the motoric examination, the upper motoric scale was 4 both right and left, and the lower motoric scale was still 0 (zero) both right and left. He was still lying on the bed with some decubitus ulcers. He could do mobilization in bed to face right and left sides with the assistant's help and still had difficulty sitting down in a wheelchair. In both cases from this article, both patients performed good rehabilitation management. Physical rehabilitation may affect the better outcome after surgery. Hachem et al wrote that conventional physical rehabilitation has a role to strengthen muscles, improve range of motion, and induce cardiorespiratory loading. It is increasingly being augmented by technologies. Aggressive and early mobilization are primary tenets of rehabilitation after SCI. ${ }^{15}$

\section{Conclusion}

In conclusion, the clinical outcome of cervical injury patients can be affected by some factors, for example, timing to diagnosis, timing to traction application, timing to surgery, and timing to rehabilitation. Depending on the institution, weekend days can also affect the delay of the COVID-19 PCR swab. MRI schedule (workdays only) and patient's optimal condition can also affect the timing to surgery. The immediate diagnosis and prompt treatment are needed to make a better outcome, especially better neurological status.

\section{Acknowledgments}

We thank Prof. Dr. R. Soeharso Orthopedics Hospital and the patients that allowed us to collect the data and publish this manuscript.

\section{Disclosure}

The authors report no conflicts of interest in this work.

\section{References}

1. American College of Surgeons. Spinal and Spinal Cord Trauma. Advanced Trauma Life Support Student Course Manual. 10th ed. 2018; 128-147.

2. Cristante A, Barros-Filho T, Marcon R, Letaif $O$, Rocha $I$. Therapeutic approaches for spinal cord injury. Clinics. 2012;67 (10):1219-1224. doi:10.6061/clinics/2012(10)16

3. Marcon R, Cristante A, Teixeira W, Narasaki D, Oliveira R, BarrosFilho T. Fractures of the cervical spine. Clinics. 2013;68 (7):1455-1461. doi:10.6061/clinics/2013(11)12

4. Cheever K, Kawata K, Tierney R, Galgon A. Cervical injury assessments for concussion evaluation: a review. $J$ Athl Train. 2016;51 (12):1037-1044. doi:10.4085/1062-6050-51.12.15

5. Schoenfeld A, Bono C, Reichmann W, et al. Type II odontoid fractures of the cervical spine: do treatment type and medical comorbidities affect mortality in elderly patients. Spine. 2011;36:879-885. doi:10.1097/BRS.0b013e3181e8e77c

6. Schoenfeld A, Le H, Bono C. Cervical spine fractures and dislocations. In: Tornetta P, Ricci W, Ostrum R, McQueen M, McKee M, Court-Brown C, editors. Rockwood and Green's Fractures in Adults. 9th. 2020:2933-3066.

7. Sjamsuhidajat R, De-jong W. Cedera Tulang Belakang dan Sumsum Tulang [Spinal and bone marrow injury]. In: Textbook of Surgery. Vol. 39. 2nd ed. Jakarta: Penerbit Buku Kedokteran EGC; 2005:822-825.

8. Baaj A, Uribe J, Nichols T, et al. Health care burden of cervical spine fractures in the United States: analysis of a nationwide database over a 10-year period. J Neurosurg Spine. 2010;13:61-66. doi:10.3171/ 2010.3.SPINE09530

9. Pull-ter-Gunne A, Aquarius A, Roukema J. Risk factors predicting mortality after blunt traumatic cervical fracture. Injury. 2008;39:1437-1441. doi:10.1016/j.injury.2008.03.008

10. Harris M, Reichmann W, Bono C, et al. Mortality in elderly patients after cervical spine fractures. $J$ Bone Joint Surg Am. 2010;92:567-574. doi:10.2106/JBJS.I.00003

11. Shresta N, Shad MY, Ulvi O, et al. The Impact of COVID-19 on Globalization. One Health. 2020;11:100180. doi:10.1016/j. onehlt.2020.100180

12. Liu Y, Shi CG, Wang XW, et al. Timing of surgical decompression for traumatic cervical spinal cord injury. Int Orthop. 2015;39:2457-2463. doi:10.1007/s00264-014-2652-z

13. Du JP, Fan Y, Zhang JN, Liu JJ, Meng YB, Hao DJ. Early versus delayed decompression for traumatic cervical spinal cord injury: application of the AOSpine subaxial cervical spinal injury classification system to guide surgical timing. Nat Eur Spine J. 2019;28:1855-1863. doi:10.1007/s00586-019-05959-6

14. Wang JH, Daniels AH, Palumbo MA, Eberson CP. Cervical traction for the treatment of spinal injury and deformity. JBJS Rev. 2014;2(5): e4. doi:10.2106/JBJS.RVW.M.00108

15. Hachem LD, Ahuja CS, Fehlings MG. Assessment and management of acute spinal cord injury: from point of injury to rehabilitation. $J$ Spinal Cord Med. 2017;40(6):665-675. doi:10.1080/107 90268.2017.1329076
Open Access Emergency Medicine

\section{Publish your work in this journal}

The Open Access Emergency Medicine is an international, peerreviewed, open access journal publishing original research, reports, editorials, reviews and commentaries on all aspects of emergency medicine. The manuscript management system is completely online and includes a very quick and fair peer-review system, which is all easy to use. Visit http://www.dovepress.com/testimonials.php to read real quotes from published authors. 